\title{
GUAMÁ BILINGÜE: UNA VISIÓN DE LOS PARTICIPANTES SOBRE GÉNERO Y SEXUALIDAD ${ }^{1}$
}

\author{
Douglas Lima de BRITO² \\ Universidade Federal do Pará
}

RESUMO: Pretende-se mostrar como alunos adolescentes de duas escolas públicas da periferia de Belém convivem e pensam sobre gênero e sexualidade. O projeto de pesquisa, ensino e extensão Guamá Bilingüe, devidamente registrado no $\mathrm{CNPq}$, recebe 30 alunos com idades entre 15-18 anos de duas escolas públicas do bairro Guamá, onde está localizada a Universidade Federal do Pará (UFPA) e onde são ministradas as aulas. O projeto busca desenvolver a cidadania através do ensino/aprendizagem do espanhol como língua estrangeira. Em consonância com Moita Lopes (2012) que afirma que só nos interessamos quando algo é importante para nós, assim é sugestivo que o professor saiba a opinião de seus estudantes sobre a identidade de gênero e a sexualidade. Ademais, como visa o mesmo autor, em uma aula de língua estrangeira pode-se abordar qualquer tema, desta forma, propõe uma discussão de identidade de gênero e sexualidade nas aulas. A pesquisa ocorre quando se apresenta ao fim do curso aos alunos do projeto um questionário com perguntas fechadas e abertas sobre suas identidades de gênero e sexualidade, suas opiniões, de suas escolas de ensino regular e etc. Assim, pode-se fazer um paralelo com o resultado de um questionário com perguntas similares do ano 2014. Dessa maneira, se atesta como ocorreu em 2014, que as escolas seguem sem discutir esses temas ainda que os alunos os discutam entre eles.

Palavra-chave: Guamá Bilingüe; Gênero e sexualidade; Língua espanhola.

RESUMEN: Se pretende mostrar como alumnos adolescentes de dos escuelas públicas de la periferia de Belém conviven y piensan sobre género y sexualidad. El proyecto de investigación, enseñanza y extensión Guamá Bilingüe, debidamente registrado en CNPq, recibe 30 alumnos con edades entre 15-18 años de dos escuelas públicas del barrio Guamá, donde está ubicada la Universidad Federal de Pará (UFPA) y donde son impartidas las clases. El proyecto busca desarrollar la ciudadanía a través de la enseñanza/aprendizaje del español como lengua extranjera. En consonancia con Moita Lopes (2012) que afirma que solo nos interesamos cuando algo es importante para nosotros, así es sugestivo que el profesor sepa la opinión de sus estudiantes acerca de la identidad de género y la sexualidad. Además, como visa el mismo autor, en una clase de lengua extranjera se puede abordar cualquier tema, de esta forma, propone una discusión de identidad de género y sexualidad en las clases. La investigación ocurre cuando se presenta al final del curso a los alumnos del proyecto un cuestionario con preguntas cerradas y abiertas sobre sus identidades de género y sexualidad, sus opiniones, de sus escuelas de enseñanza regular y etc. Así, se puede hacer un paralelo con el resultado de un cuestionario con preguntas similares del año 2014. De esa manera, se atesta, como ocurrió el 2014, que las escuelas siguen no discutiendo esos temas aunque los alumnos los discuten entre ellos.

Palabra-clave: Guamá Bilingüe; Género y sexualidad; Lengua española.

\footnotetext{
${ }^{1}$ Artigo produzido com base na dissertação intitulada: Homosexualidad y Guamá Bilingüe: una enseñanza sin prejuicios. Defendida em 2014, na Universidade Federal do Pará, na Faculdade de Letras Estrangeiras Modernas. 2 Professor Substituto de Língua Espanhola, na Universidade Federal do Pará, ano 2016. Contato: douglasbrito500@gmail.com
} 


\section{Introducción}

La sexualidad está presenta en las charlas, en la vida de los jóvenes en Brasil, y no solo el tema de la sexualidad, sino también las interpretaciones de género social (hombre, mujer), y de todos los demás temas que se relacionan con ellos, por ejemplo, la homosexualidad y la heterosexualidad.

Como el proyecto Guamá Bilingüe recibe jóvenes y esos temas están presentes en sus vidas, queremos saber cómo los participantes comprenden los temas expuestos (género y sexualidad). Para de esa forma ayudar a sacar los prejuicios y las dudas naturales que surgen en esa fase de la vida.

Además de ser importante que los profesores sepan cómo piensan, comprenden e interpretan, no solo en sus vidas privadas y públicas, como también en los espacios educacionales. Incluso, con este trabajo buscamos saber cómo las escuelas abordan estos temas de género y sexualidad en sus interiores, con sus alumnos y profesores, si existe alguna discusión sobre eso.

Para eso, utilizamos un cuestionario preguntando a los alumnos sobre qué saben sobre estos temas y si se los discuten en sus escuelas y en el proyecto. Y como percibimos en 2014, no se ha cambiado tanto, la escuela sigue un paso atrás mientras los alumnos sí los discuten entre ellos.

Este articulo está estructurado con la presenta introducción, seguida de la aclaración de Guamá Bilingüe, después empieza el marco teórico con las maneras que son comprendidas la idea de escuela, de los profesores / becarios, de género y sexualidad, de prejuicio, homofobia, en seguida mostramos la metodología utilizada, el análisis de los cuestionarios usados, y por fin, la conclusión del articulo y las referencias que basan este trabajo.

\section{Guamá Bilingüe}

Es un proyecto de investigación, extensión y enseñanza registrado en $\mathrm{CNPq}$, con acciones extensionistas involucrando dos escuelas públicas del barrio Guamá, en la ciudad de Belém, en Pará. El Proyecto Guamá Bilingüe usa la lengua española para desarrollar la ciudadanía de sus participantes, con el intento de crear en cada uno de ellos la responsabilidad de vivir en sociedad, respetando lo diferente.

El Proyecto Guamá Bilingüe fue creado en el año de 2010, coordinado por la profesora M.Sc. Rita de Cássia Paiva, subsidiado por Pró-Reitoria de Ensino e Graduação (PROEG), por medio del Programa de Apoio a Projetos de Intervenção Metodológica (PAPIM), ligada a la Faculdade de Letras Estrangeiras Modernas (FALEM), del Instituto de Letras e Comunicação (ILC), de Universidade Federal do Pará (UFPA). (BRITO, 2014). 
Las clases ocurren tres veces por semana, con duración de una hora cada clase, recibiendo jóvenes de quince a dieciocho años de la enseñanza secundaria. El Proyecto tiene dos becarios que imparten las clases, y además, fue elegido el Guamá por ser uno de los barrios periféricos de la ciudad y también por ser donde está localizada la Universidad.

\section{La escuela}

En las escuelas brasileñas hay un universo heterogéneo en su interior, en el cual los alumnos encuentran y desarrollan los criterios que llevaran por sus vidas en relación a sí mismo y a los demás. Junqueira (2009, p.39) señala la importancia central de la escuela, mismo con sus dificultades, que no son los enfoques de este trabajo, la escuela es un espacio para crear nuevos estándares de aprendizaje, convivencia, y desestabilizar valores y prejuicios. Por eso, Guamá Bilingüe siendo un espacio educacional, no puede estar lejos de la responsabilidad de desarrollar el aprendizaje y ciudadanía de sus estudiantes.

Basándonos en Azevedo (2012, p. 55-56), las escuelas, generalmente, trabajan sobre una mirada monocultural, dejando de trabajar la construcción de los discursos y de las identidades sociales, simplemente ignorando las diferencias existentes en todos los ambientes educacionales. Aquí comprendemos monocultural como bien define Moita Lopes (2012, p. 10), "sujeito único e homogêneo (homem, branco, heterossexual e europeu)".

Esta Heteronormatividad termina creando un espacio poco propicio para una discusión más reflexiva y crítica sobre las categorías sociales (AZEVEDO, 2012, p. 56). En este punto, el Proyecto Guamá Bilinguie busca un lugar donde se pueda discutir las identidades sociales, mostrando a los alumnos la pluralidad existente en la sociedad a través de la lengua extranjera.

A voz do/a professor/a, a fonte da autoridade e transmissora única do conhecimento legítimo, é substituída por múltiplas vozes, ou melhor, é substituída pelo dialogo, no qual todos/as são igualmente falantes e ouvintes, todos/as são capazes de expressar (distintos) saberes. (LOURO, 2008, p. 113).

Aprovechando las distinciones existentes en las clases, usamos para mostrar que nadie es igual, y las diferencias son normales en cualquiera sociedad, pues como afirma Rios (2009, p. 56), la convivencia con distintos grupos y la educación son útiles como posibles respuestas. Sobre todo, buscamos respetar las diferencias, además que los homosexuales abren un campo importante para discusiones a respeto a la sexualidad y a la diversidad sexual, principalmente para jóvenes en los cuales la sexualidad está bastante presente, o sea, las actividades educacionales planeadas deben considerar que los heterosexuales y los homosexuales pueden aprender mucho sobre su propia sexualidad, en convivio y discusiones con diferentes sexualidades (SEFFNER, 2009, p. 135).

El Proyecto Guamá Bilingüe intenta crear un espacio que no sea solo educacional, sino también un espacio social, que la clase sea un ambiente en la cual ocasione cuestionamientos y reflexiones sobre la sociedad y sobre uno mismo, que al final del año 
salgan personas transformadoras de una realidad que pueda ser más justa e igualitaria para todos/as que están a su alrededor (GIESEL, 2012, p. 101 e 110). Muchas escuelas ignoran esa cuestión de pluralidad sexual en sus interiores por creer que el deseo es exclusivo de los heterosexuales, o sea, se niega la posibilidad que haya deseos por alguien del mismo sexo entre sus alumnos. (LOURO, 2008, p. 135).

Según Moita Lopes (2012, p.11), "só nos envolvemos na construção do significado quando aquilo do que falamos, lemos ou escrevemos é relevante ou significativo para nós mesmos". Por eso, todo lo que enseñamos necesita de un significado para el estudiante, una idea práctica para su vida, que venga a añadir nuevas visiones de mundo y no podemos distanciar la clase de su cotidiano.

Devemos ter em mente que as interações ocorridas no espaço escolar devem ser intersectadas com a realidade do aluno para que essas interações possam contribuir significamente para o seu desenvolvimento, o que, consequentemente, pode privilegiar a emersão de novos saberes que podem nos ajudar a construir uma sociedade mais justa e igualitária. (GIESEL, 2012, p. 113).

Cuando el alumno es invitado a participar en clase, exponer sus creencias, sus experiencias, este intercambio de pensamiento, de ideas, enriquece la enseñanza y el aprendizaje. Es de grande relevancia no solo a los jóvenes participantes del proyecto, sino también a aquellos que imparten las clases, o sea, el profesor.

\section{Profesores / becarios}

El Proyecto Guamá Bilingüe es importante no solo para los alumnos que de él participan, sino también para los becarios que imparten las clases y tienen la oportunidad de vivir un poco esta profesión, ya que serán pronto profesores. Además, los becarios tienen todo el apoyo de la coordinadora y del grupo de investigación, ellos aun pasan por una preparación al comienzo del año y hay reuniones constantes durante el año.

En este Proyecto, el profesor necesita desnudarse de sus propios prejuicios, porque los alumnos ya son marginados por vivir en un barrio periférico de la capital. Y también creemos ser inaceptable que el docente sea un transmisor o retransmisor de prejuicios contra un individuo o grupo social.

O professor é um importante adulto de referência, por vezes a primeira pessoa fora do círculo familiar com quem a criança ou o adolescente pode conversar com franqueza sobre temas de seu cotidiano. Novamente repito: a escola é um lugar de aprendizagens, e o professor deve conduzir sua relação com os alunos no sentido de explorar as possibilidades desta aprendizagem. (SEFFNER, 2009, p. 132). 
Aquí entra un complemento para la formación docente de este becario, que es un estudiante de curso superior de la carrera de Letras - Español, y muchas veces no tiene la oportunidad de recibir una formación más direccionada para los temas sociales, como afirma Moita Lopes (2012, p. 10), "porque os professores normalmente foram formados dentro de tais discursos, que ainda circulam na universidade". Discursos que privilegian la heterosexualidad, que no dan atención a los cambios actuales en nuestra sociedad, a los géneros, a la sexualidad y a las razas, o sea, lo social como un todo, "é necessário formar professores ensinando -os a entender que linguagem é prática social" (MOITA LOPES, 2012, p. 12; LEFFA, 2012, p. 392; AZEVEDO, 2012, p. 56-57).

Los becarios/profesores necesitan tener un posicionamiento más crítico, ellos deben estar preparados a la hora de la discusión de los "temas sensibles", necesitan estar con sus percepciones de mundo y del entorno muy bien pensados. Sabido es que el barrio Guamá, donde están ubicadas las escuelas, la Universidad y donde viven los alumnos son discriminados por el gobierno, la prensa y por la sociedad de una manera general, por haber altos índices de criminalidad.

"Aceitar a proposta de trabalhar em uma perspectiva crítica significa enfrentar o desafio de problematizar muitas de nossas próprias concepções" (FREITAS \& PESSOA, 2012, p. 155). Solamente así, los becarios/profesores van a estar preparado para recibir a esos alumnos, que muchas veces llegan en las clases del proyecto descreyendo en la educación y en una mejora de sus vidas.

Como professores/as críticos/as e atentos/as aos problemas sociais, precisamos construir e reconstruir espaços nas quais a diferença seja o caminho para direitos mais igualitários entre homens e mulheres, pessoas negras e pessoas brancas, pessoas ricas e pessoas pobres, homossexuais e heterossexuais etc. (FREITAS \& PESSOA, 2012, p. 151).

Con todo ello, el Proyecto Guamá Bilingüe proporciona a sus becarios reflexiones sobre sus formas de enseñanza, sus posicionamientos frente a ciertos temas para que no quede la sensación de "que as pessoas devem evitar discutir questões sensíveis, e não contestar o que já está construído em termos de manutenção do status quo, porque eles não serão ouvidos". (FERREIRA, 2012, p.35).

A ambição pode ser "apenas" subverter os arranjos tradicionais de gênero na sala de aula: inventando formas novas de dividir os grupos para os jogos ou para os trabalhos; promovendo discussões sobre as representações encontradas nos livros didáticos ou nos jornais, revistas e filmes consumidos pelas/os estudantes; produzindo novos textos, não-sexistas e não-racistas; investigando os grupos e os sujeitos ausentes nos relatos da História oficial, nos textos literários, nos "modelos" familiares; acolhendo no interior da sala de aula as culturas juvenis, especialmente em suas construções sobre gênero, sexualidade, etnia, etc. (LOURO, 2008, p. 124).

De acuerdo con Ferreira (2012, p.37-38), "a forma como os/as professores/as, por falta de conhecimento no assunto, podem reproduzir 'as relações existentes' no Brasil", nos 
hace constantemente lamentar la falta de una discusión más presente sobre las cuestiones sociales, en nuestro caso, la homosexualidad, en la formación de profesores. En consonancia con Azevedo (2012, p.56) sabemos que "os modos como a linguagem que utilizamos podem reproduzir hierarquizações, preconceitos, estigmas e toda sorte de verdades", percibimos que "é indispensável questionar não apenas o que ensinamos, mas o modo como ensinamos e que sentidos nossos/as alunos/as dão ao que aprendem” (LOURO, 2008, p. 64).

Por lo tanto, el Proyecto Guamá Bilinguie, hasta aquí, desarrolla favorablemente dos lados, el de los estudiantes, porque aprenden la lengua española y amplían sus visiones del mundo, y el de los becarios/profesores, porque participan de un proyecto de enseñanza, investigación y extensión, se aproximan del mundo laboral y derriban algunas barreras internas que eventualmente aun tengan.

\section{Género y sexualidad}

Varios estudios evidencian que la homosexualidad siempre estuvo presente en la historia, sea como prácticas sociales y/o sexuales, en distintos pueblos, épocas y clases sociales, desde Grecia pasando por Roma hasta China. Aunque dentro de sus tradiciones, la práctica homosexual se hacía presente en las antiguas sociedades, sin embargo, con la expansión y fortalecimiento del Cristianismo se inicia el rechazo a la homosexualidad (FILHO, 2009, p. 100-102; LOURO, 2009, p. 88; PRADO \& MACHADO, 2012, p. 15).

En primer lugar, de una manera breve, Prado \& Machado traen una definición,

Mais que o comportamento sexual entre pessoas do mesmo sexo, é mais que a orientação do desejo sexual para pessoas do mesmo sexo, e é mais que nutrir afetos por pessoas do mesmo sexo. A homossexualidade pode abranger todas as características, parte delas ou ainda ultrapassar essas definições através dos complexos arranjos culturais que o ser humano é capaz de criar. (PRADO \& MACHADO, 2012, p. 28).

La homosexualidad ha ido recibiendo una visión de anormalidad en la historia, discursos de instituciones fueron haciendo la heteronormatividad como correcta, "o modelo 'normal' é a família nuclear constituída por um casal heterossexual e seus filhos. Essa forma de organização social é, na verdade, mais que normal, ela é tomada como natural" (LOURO, 2008, p. 134). En el momento que se naturaliza esta relación, abandonamos las demás formas de relación humana, por ejemplo, las parejas sin hijos, las mujeres que no quieren ser madres, y toda la pluralidad sexual desarrollada por el ser humano.

Em nossa sociedade, a não heterossexualidade foi gravemente condenada pelo discurso hegemônico, que, influenciado pelo discurso religioso e médico-científico, legitimou instituições e práticas sociais baseadas em um conjunto de valores heteronormativos, os quais levaram à discriminação negativa e à punição de diversos comportamentos sexuais, sob a acusação de crime, pecado ou doença. (PRADO \& MACHADO, 2012, p. 12). 
Todos los comportamientos que se alejan de la definición de heteronormativo no son considerados ciertos, porque están fuera de lo natural, va en contra la naturaleza, sin embargo: ¿Cuál es la naturaleza del Ser?, ¿Qué es realmente heteronormativo? Y pensamos si solo la homosexualidad es aceptada como no-heteronormativo. "Mesmo na ausência de consenso, a homossexualidade vem ganhando cada vez mais espaço na arena pública contemporânea e despertando novas inquietações, dilemas e mitos" (PRADO \&MACHADO, 2012, p. 28). En este contra-punto surgen los prejuicios.

\section{Prejuicio}

Prejuicio es una idea negativa o equivocada expresada de diferentes formas por individuos y/o grupos en contra a otros individuos y/o grupos definidos como inferiores (RIOS, 2009, p. 55). Prado \& Machado (2012, p. 25) complementan afirmando que el prejuicio, que es un sentimiento y un pensamiento, se manifiesta cuando simplificamos la complejidad existente en el otro individuo.

O preconceito se instala a partir do momento em que a diferenciação grupal não permite um sentimento de comparação que não seja de exclusividade, isto é, uma comparação que exige hierarquização, já que a existência de uma posição ameaça a soberania indenitária de outra. [...] A base de afirmação do preconceito se sustenta nas práticas cotidianas, que, informadas pelas logicas de poder exclusivo e pela noção de direitos substancial, sustentam a naturalização do significado da diferenciação grupal. (PRADO \& MACHADO, 2012, p. 25-26).

Entre los distintos prejuicios existentes en las relaciones humanas, quedaremos con la homofobia, ella que se encuentra todos los días en las vidas de todos, tanto de aquellos que la sufren como de los que la practican. La homofobia se materializa en la distinción de un grupo llamado heterosexual, que por razones históricas se naturalizó como cierta, única y verdadera, y de los no-heterosexuales, que por consecuencia, son anomalías, errores y problemas. En este caso, el primer grupo detiene un poder sobre el segundo, por el primero ser lo "normal", "natural" y no aceptar ser comparado con el segundo, porque en el momento que los dos grupos fueran, en nivel de poder, iguales, ya no habrá más la soberanía de la heteronormatividad.

Nesse contexto, as práticas e sujeitos homossexuais permaneceram posicionados em condições subalternas no discurso hegemônico contemporâneo, fomentando a formação do preconceito contra homossexuais como um importante mecanismo de manutenção de hierarquias sociais, morais e políticas. Estamos chamando de discurso hegemônico aquele discurso capaz de criar formas e práticas de consentimento, de modo a transformar uma experiência particular (neste caso, a experiência heterossexual burguesa) em pretensamente universal, inferiorizando ou invisibilizando quaisquer outras possibilidades da experiência social. (PRADO \& MACHADO, 2012, p. 13). 
Prado \& Machado (2012, p. 24) siguen apuntando las causas y consecuencias de subyugar (la inferiorización) un grupo social, aquí, los homosexuales

Esta subalternidade pode se estender desde a instalação de práticas legalizadas ou ilegalizadas até o menor acesso a políticas públicas, atravessadas pelos mecanismos produzidos pelo preconceito. Estes mecanismos [...] silenciam a desigualdade dos direitos sociais e sustentam uma inclusão perversa em âmbitos da vida social, como a escola, a família, a saúde, a cultura e as relações sociais, de onde derivam muitos dos sofrimentos experienciados individualmente. (PRADO \& MACHADO, 2012, p. 24).

\title{
Homofobia
}

En segundo lugar, Rios (2009, p.59) defiende que "homofobia é a modalidade de preconceito e discriminação direcionada contra homossexuais", y sigue mencionando la homofobia como un cualquier ataque a los derechos humanos y daños a la libertad de cualquier campo de la vida, sea económico, cultural, social y etc. Siendo intencional o no intencional (RIOS, 2009, p. 73).

Louro (2009, p. 28-29) también define la homofobia como un "terror", un miedo de los heterosexuales de perdieren su género, femenino y masculino "puros", como si hombres y mujeres fueran sufrir una pérdida de definición sexual, cuanto a esto vamos a dialogar un poco más a frente, pues tiene una fuerte relación con las "relaciones de poder" en una sociedad. Con una rápida definición de heteronormativo y géneros, Freitas \& Pessoa (2012, p. 158) mencionan

\begin{abstract}
Além de abordar discussões em torno das desigualdades entre homens e mulheres, esse reconhecimento do gênero como uma construção sociocultural, colabora com a problematização da ideia de que homens e mulheres devem ser ou se comportar de determinadas formas, adotando, ao longo de suas vidas, identidades fixas e permanentes. (FREITAS \& PESSOA, 2012, p. 148).
\end{abstract}

Outro nítido traço de homofobia se expressa na indiferença cultivada em relação ao sofrimento e aos demais efeitos da homofobia na vida de nossos/as estudantes" (JUNQUEIRA, 2009, p. 27). O sea, cuando menospreciamos el sufrimiento de nuestros alumnos homosexuales, fingiendo que no vemos los "chistes" homofóbicos que ellos reciben o pensando que a los gays no les importan.

No âmbito da sexualidade, o preconceito social produziu a invisibilidade de certas identidades sexuais, garantindo a subalternidade de alguns direitos sociais e, por sua vez, legitimando práticas de inferiorizações sociais, como a homofobia. O preconceito, neste caso, possui um funcionamento que se utiliza, muitas vezes, de atribuições sociais negativas advindas da moral, da religião ou mesmo das ciências, para produzir o que aqui denominamos de hierarquia sexual, a qual é embasada em um conjunto de valores e práticas 
sociais que constituem a hetenormatividade como um campo normativo e regulador das relações humanas. (PRADO \& MACHADO, 2012, p. 70).

La exclusividad de ser heterosexual, y que el no-heterosexual deber se someter, crea una jerarquización de identidad, que se muestra y se reitera, y se confirma en las actitudes homofóbicas, aunque no parezca discriminatoria, por ser algunas ya naturalizadas en la sociedad."Assim, a hierarquia pode ser reconhecida como uma relação de opressão, desde que para isso esta relação seja tomada e reconhecida, pela comparação social, como uma relação que oprime um dos atores em jogo" (PRADO \& MACHADO, 2012, p. 69). Los profesores de lengua extranjera, debemos también intentar romper con esas "relaciones de poder", que muchas veces aparecen en los discursos, tanto en lengua materna como en lengua extranjera.

\section{Metodología}

Comenzamos con la lectura de la literatura del área, después pasamos la construcción de un cuestionario que fue basado en las definiciones de Günther (2003) con diez preguntas en portugués, para mejor comprensión de los participantes. Los cuestionarios tienen preguntas sobre los temas propuestos en este trabajo, con preguntas abiertas y cerradas. Él fue contestado por ocho estudiantes que estaban presentes en el día que se lo pasó en clase. El otro paso fue iniciar el análisis de forma cuantitativa y cualitativa de estos instrumentos utilizados, los numeramos de 1 hasta el 8. Pasado eso, se comenzó la escritura de este artículo.

\section{Análisis de los datos}

En este apartado vamos a iniciar el análisis de los cuestionarios contestados. Para una mejor comprensión, vamos comenzar cada párrafo con la pregunta referente en el cuestionario, pero diferente del original decidimos traducir al español las preguntas, y seguido por las conclusiones de los análisis hechos.

¿Qué es homosexualidad? 75\% escribieron que es algo que ver con gusto u opción de cada uno, $12,50 \%$ dijo que no es normal y un $12,50 \%$ escribió que no sabe decir. O sea, la mayor parte de los alumnos que contestaron que la opción de cada uno sobre su sexualidad, y una persona contestó que no es normal la homosexualidad y no dijo que no sabía cómo contestar lo que es la homosexualidad.

¿Qué es homofobia? 50\% escribieron que es un prejuicio, 12,50\% escribió que no sabe contestar que sería la homofobia, y 37,50\% contestaron con otras respuestas, no solamente que era un prejuicio, por ejemplo, en el cuestionario número 8 "É quando uma pessoa não respeita a mesma opção da outra e acaba agredindo físicamente oralmente".

¿Qué es heterosexualidad? $75 \%$ contestaron que es cuando una persona de un sexo se enamora por una persona de un sexo opuesto al suyo, $12,50 \%$ no subo contestar que sería la heterosexualidad, $12,50 \%$ contestó diferente, ese escribió así: cuestionario 6. "Não tenho nada contra cada um tem direito de escolher o que quer para sua vida." 
¿Se discuten estos temas en su escuela? $50 \%$ dijeron que No, que no se discute, $25 \%$ escribieron que Sí, se discute estos temas en las escuelas, $25 \%$ contestaron con un Tal vez se discute en las escuelas que ellos estudian. El cuestionario 1 dijo: "Sim, de vez em quando", cuestionario 2: "Muito difícilmente, $[\ldots]$ ".

¿Se discuten estos temas en Guamá Bilingüe? 25\% escribieron que Sí, que se discute estos temas en el proyecto, $37,50 \%$ contestaron que No, que no se discute estos temas, y $37,50 \%$ contestaron que solamente se discute el tema de prejuicio, que no se discute estos temas separados, pero dentro del contexto de prejuicio de una manera general. Cuestionario 8: "Falaram apenas de preconceito em forma geral". Cuestionario 3: "Até aqui também não tínhamos tido está oportunidade.”

¿Cambió alguna opinión sobre estos temas en Guamá Bilingüe? La mayoría, 62,50\% contestaron que No, que no cambiaron ninguna opinión porque ellos no tienen prejuicios sobre estos temas y tienen muy claro los conceptos, $12,50 \%$ que Sí, que cambió, y 12,50\% dijo que tal vez tenga cambiado alguna opinión. El cuestionario 5 no contestó esa pregunta, y el cuestionario dijo: "Um pouco, tivemos um conhecimento a respeito disso, mas não mudou muito, ainda há muitas pessoas preconceituosas". El cuestionario 7: "Não muito".

¿Creer ser importante discutir sobre estos temas? ¿Por qué? 100\%, todos escribieron que Sí, que es importante discutir estos temas. Y sobre los motivos tenemos, cuestionario 2: "Sim, porque há muitas pessoas que não sabem do que se trata e por isso motivo acabam tendo atitudes mais que podem prejudicar a outros". Cuestionario 4: "Sim, isso é algo tão comum atualmente, que se nós discutíssemos mais, talvez, esse preconceito venha ser extinto". El cuestionario 7: "Sim, é importante porque se alguém tem preconceito e começa a saber sobre o assunto, o que isso causa para pessoa que sofre preconceito, ela pode repensar suas atitudes e deixar de ser pessoas preconceituosas."

¿Qué es prejuicio? Aquí presento cuatro respuestas que nos pareció las más interesantes, el cuestionario 2 dijo que: "É todo tipo de críticas feita por alguém por qualquer fato que seja, social, racial e cultural", el número 3: "É tudo aquilo que eu posso críticar mesmo sem saber o seu fundamento", el cuestionario 5 escribió que prejuicio es: "Preconceito é uma pessoa que quer ser superior a outras pessoas, por ser diferente. Tem um pensamento ruim ou bom sem conhecer". Cuestionario 7 : "É a atitude de algumas pessoas que não gostam de outra pessoas por causa da cor delas, religião, classe e etc".

¿Abandonó algún prejuicio durante el Guamá Bilingüe? El 75\% escribieron que No, porque según ellos no tienen prejuicios para abandonar, y el $25 \%$ contestaron que Sí, que abandonaron algún prejuicio, como ejemplo traemos el cuestionario 6: "Sim, vários, principalmente o racismo".

Para finalizar, la última pregunta, la de número diez, ¿Te consideras? Entre las opciones, $87,50 \%$ se declararon heterosexuales, $12,50 \%$ bisexuales, y nadie se declaró homosexual u otros. 


\section{Conclusión}

En el Proyecto Guamá Bilingüe, mostramos para los estudiantes que los prejuicios son dañosos para una convivencia harmoniosa entre todos, que la quiebra de estos estándares de distinción grupal y la igualdad entre los individuos es benéfica y no al revés.

É essencial, então, entender a linguagem como ação social e nossas práticas discursivo-identitárias como socioculturalmente construídas. Não há contextos sociais prontos e acabados; eles são produzidos ativamente em nossas interações diárias. (AZEVEDO, 2012, p. 56-57).

Discutir la homosexualidad en clase es importante para construir ciudadanos más preparados para la convivencia con los distintos grupos presentes en nuestra sociedad. Así como todo el entorno de la homosexualidad, los prejuicios, la homofobia, la construcción de todo eso. Estamos en todo momento construyendo, reconstruyendo estándares sociales, como las lenguas extranjeras influencian en la visión sociocultural de uno, la usamos como vehículo de reflexión, alumnos y profesores, de nuestras acciones sociales cotidianas.

De tal forma percibimos la importancia del proyecto en la vida de estos estudiantes y la falta de esa discusión (sobre género, sexualidad y demás términos) en las escuelas de los participantes. De igual manera también la falta de esa discusión dentro del propio proyecto. Sin embargo, se está escribiendo unidades futuros que incluyeran los temas propuestos de una manera más enfática y presente.

\section{Referencia}

AZEVEDO, Aline da Silva. A sala de aula de língua inglesa como fórum de discussão sobre as identidades de raça: Compartilhando uma experiência intervencionista. In: FERREIRA, Aparecida de Jesus (Org.). Identidades sociais de raça, etnia, gênero e sexualidade: praticas pedagógicas em sala de aula de línguas e formação de professores/as. São Paulo. Ed. Pontes, 2012.

BRITO, Douglas Lima de. Lo Social en las Clases de Guamá Bilingüe. VIII Encontro Internacional de Letras. Foz do Iguaçu, 2014.

FERREIRA, Aparecida de Jesus. Identidades sociais de raça/etnia na sala de aula de língua inglesa. In: FERREIRA, Aparecida de Jesus (Org.). Identidades sociais de raça, etnia, gênero e sexualidade: praticas pedagógicas em sala de aula de línguas e formação de professores/as. São Paulo. Ed. Pontes, 2012.

FILHO, Alípio de Souza. Teorias sobre a Gênese da Homossexualidade: ideologia, preconceito e fraude. In: JUNQUEIRA, Rogério Diniz (Org.) Diversidade Sexual na Educação: problematização sobre a homofobia nas escolas. Brasília: Mec. e UNESCO, 2009. 
FREITAS, Marco Túlio de Urzêda; PESSOA, Rosane Rocha. Gênero, sexualidade e ensino crítico de línguas estrangeiras: intersecções com a formação de professores/as. In: FERREIRA, Aparecida de Jesus (Org.). Identidades sociais de raça, etnia, gênero e sexualidade: praticas pedagógicas em sala de aula de línguas e formação de professores/as. São Paulo. Ed. Pontes, 2012.

GIESEL, Cláudia Cristina Mendes. Uma abordagem sociointeracionista humanizadora para o ensino de línguas estrangeiras: Gênero na sala de aula. In: FERREIRA, Aparecida de Jesus (Org.). Identidades sociais de raça, etnia, gênero e sexualidade: praticas pedagógicas em sala de aula de línguas e formação de professores/as. São Paulo. Ed. Pontes, 2012.

GÜNTHER, Hartmut. Como Elaborar um Questionário. Universidade de Brasília, 2003.

JUNQUEIRA, Rogério Diniz. Educação e Homofobia: o reconhecimento da diversidade sexual para além do multiculturalismo liberal. In: JUNQUEIRA, Rogério Diniz (Org.) Diversidade Sexual na Educação: problematização sobre a homofobia nas escolas. Brasília: Mec. e UNESCO, 2009.

Homofobia na escola: um problema de todos. In: JUNQUEIRA, Rogério Diniz (Org.) Diversidade Sexual na Educação: problematização sobre a homofobia nas escolas. Brasília. Mec. e UNESCO, 2009.

LEFFA, Vilson. Ensino de línguas: passado, presente e futuro. Revistas de estudos da linguagem: Belo Horizonte, 2012. v. 20, n. 2.

LOURO, Guacira Lopes. Heteronormatividade e homofobia. In: JUNQUEIRA, Rogério Diniz (Org.) Diversidade sexual na educação: problematizações sobre a homofobia na escola. Brasília. MEC e UNESCO, 2009.

Gênero, sexualidade e educação: Uma perspectiva pós-estruturalista. 10.ed. Petrópolis, RJ: Vozes, 2008.

MOITA LOPES, Luiz Paulo da. Linguagem e escola na construção de quem somos. In: FERREIRA, Aparecida de Jesus (Org.). Identidades sociais de raça, etnia, gênero e sexualidade: praticas pedagógicas em sala de aula de línguas e formação de professores/as. São Paulo. Ed. Pontes, 2012.

PRADO, Marcos Aurélio Máximo; MACHADO, Frederico Viana. Preconceito contra homossexuais: A hierarquia da invisibilidade. $2^{\circ}$ ed. São Paulo: Cortez, 2012.

RIOS, Roger Raupp. Homofobia na perspectiva dos Direitos Humanos e no contexto dos estudos sobre preconceito e discriminação. In: JUNQUEIRA, Rogério Diniz (Org.) Diversidade sexual na educação: problematizações sobre a homofobia na escola. Brasília. MEC e UNESCO, 2009.

SEFFNER, Fernando. Equívocos e armadilhas na articulação entre diversidade sexual e politicas de inclusão escolar. In: JUNQUEIRA, Rogério Diniz (Org.) Diversidade sexual na educação: problematizações sobre a homofobia na escola. Brasília. MEC e UNESCO, 2009. 